\title{
EFEKTIVITAS PENERAPAN MODEL FAMILY CENTERED NURSING TERHADAP TINGKAT KEMANDIRIAN KELUARGA DALAM PENANGANAN MALARIA PADA ANAK DI WILIAYAH KERJA PUSKESMAS SANGGENG MANOKWARI
}

\author{
EFFECTIVENESS OF THE IMPLEMENTATION OF FAMILY CENTERED NURSING MODEL ON THE FAMILY \\ INFRASTRUCTURE RATE IN MALARIA HANDLING ON CHILDREN IN WILIAYAH WORKING OF HEALTH PUSKESMAS \\ SANGGENG MANOKWARI
}

\author{
Ivonne J. Fabanjo, Maria Loihala \\ Poltekkes Kemenkes Sorong
}

ABSTRAK
Berdasarkan hasil survei riset kesehatan dasar (Riskesdas) tahun 2013 Papua, Papua Barat dan Nusa tenggara timur merupakan 3 provinsi dengan insiden malaria tertinggi. Salah satu konsep pemberdayaan keluarga yang sesuai dengan teori dan konsep keperawatan yang dapat diterapkan pada keluarga adalah Family Centered Nursing. Penerapan model Family Centered Nursing ini khususnya pada anak dengan Malaria bertujuan untuk melihat kemandirian keluarga dalam penganan anak dengan malaria, melakukan pendidikan kesehatan pada keluarga, melakukan pembinaan bagi keluarga sehingga keluarga mampu mengatasi masalah kesehatannya khususnya dalam penaganan malaria.

Tujuan Penelitian adalah untuk mengetahui efektivitas dari penerapan model Family Centered Nursing terhadap terhadap Kemandirian keluarga dalam penanganan malaria pada Anak di wiliayah kerja Puskesmas Sanggeng Manokwari.

Penelitian ini menggunakan jenis penelitian Quasi Eksperimen dengan Pre-Post test Without control Group yang mencari efektifitas atau pengaruh antar variabel dengan pendekatan crossectional. Populasi dalam penelitian ini adalah Orang tua yang membawa anaknya ke Puskesmas Sanggeng yang terdiagnosis malaria tersiana berdasarkan hasil pemeriksaan Laboratorium mulai bulan Oktober s/d November 2017. Sampel pada penelitian ini berjumlah 30 responden. Instrument penelitian menggunakan kuisioner. Tehnik pengumpulan data yaitu data primer dan sekunder. Analisa Data secara analisa univariat dan bivariat. Data diolah dengan menggunakan Program SPSS versi 19.

Hasil penelitian menunjukkan bahwa skor rerata pengetahuan sebelum dan sesudah penerapan Model Family Centered Nursing mengalami peningkatan sebesar 22,4 dan tingkat kemandirian keluarga mengalami peningkatan sebesar 0,88. Hasil analisis lebih lanjut didapatkan nilai $p$-Value 0,000 yang berarti adaperbedaan yang signifikan. Skor rata-rata pengetahuan dan tingkat kemandirian keluarga sebelum dan sesudah diberikan informasi.

Kesimpulan bahwa dari hasil penelitian yaitu responden dalam penelitian ini adalah ibu dengan usia antara 24 sampai 46 tahun. Responden mempunyai tingkat pendidikan paling banyak dengan tingkat pendidikan SMA dan paling terendah dengan pendidikan $\mathrm{SD}$, dan sebagian besar dari suku Papua, skor pengetahuan keluarga lebih rendah sebelum penerapan model bila dibandingkan dengan setelah penerapan model, tingkat kemandirian keluarga lebih rendah sebelum penerapan model bila dibandingkan setelah penerapan model, dan ada peningkatan yang signifikan skor pengetahuan dan tingkat kemandirian keluarga sebelum dan setelah penerapan model.

$\begin{array}{ll}\text { Kata Kunci } & : \text { Family Centered Nursing, Malaria } \\ \text { Daftar Pustaka } & : 2008-2017\end{array}$

\section{ABSTRACT}

Based on the results of the basic health research survey (Riskesdas) in 2013 Papua, West Papua and East Nusa Tenggara are the 3 provinces with the highest incidence of malaria. One of the concepts of family empowerment in accordance with the theory and concept of nursing that can be applied to the family is Family Centered Nursing. The implementation of the Family Centered Nursing model, especially in children with Malaria, aims to look at family self-reliance in child malnutrition with malaria, to conduct family health education, to coach for families so that families can overcome their health problems, especially in malaria handling.

The purpose of this research is to know the effectiveness of Family Centered Nursing model applied to family self-reliance in handling malaria in children in the work of Puskesmas Sanggeng Manokwari.

This research uses experimental Quasi Experimental type with Pre-Post test Without control Group which search for effectiveness or influence between variables with crossectional approach. The population in this study are parents who bring their children to Puskesmas Sanggeng diagnosed malaria tertiana based on Laboratory examination results from October to November 2017. The sample in this study amounted to 30 repsonden. The research instrument used questionnaires. Data collection techniques are primary and secondary data. Univariate and bivariate analysis. Data is processed by using SPSS Program version 19.

The results showed that the average score of knowledge before and after the application of the Family Centered Nursing Model increased by 22.4 and the family self-sufficiency rate increased by 0.88 . Further analysis results obtained p-Value 0,000 which means significant differences. Average score of knowledge and level of self-sufficiency before and after being informed.

Conclusion that from result of research that is responder in this research is mother with age between 24 until 46 year. Respondents had the highest level of education with high school education and the lowest level with primary school education, and most of the Papuan tribe, lower family knowledge scores prior to application of the model when compared to after application of the model, the level of family independence was lower before application of the model when compared application of the model, and there was a significant increase of knowledge scores and levels of family independence before and after application of the model.

Keywords: Family Centered Nursing, Malaria Bibliography: 2008 - 2017 


\section{A. Pendahuluan}

Malaria masih merupakan penyakit infeksi menular yang disebabkan oleh sporozoa genus plasmodium dan ditularkan melalui gigitan nyamuk. Hampir setengah dari populasi dunia berisiko terkena malaria. Pada tahun 2015, ada sekitar 212 juta kasus malaria dan diperkirakan 429.000 kasus kematian akibat malaria. Langkahlangkah pencegahan dan pengendalian yang meningkat telah menyebabkan penurunan angka kematian 25\% secara global sejak 2010 (WHO, 2017).

Epidemiologi malaria pada anakanak sulit untuk dinilai karena sebagian besar gejala klinis tidak spesifik dan sebagian besar kasus terjadi di tempat di mana tidak ada pemeriksaan rutin yang tersedia (Schumacher \& Spinelli, 2012). Anak di bawah 5 tahun merupakan salah satu kelompok yang paling rentan terkena malaria. Diperkirakan ada 429.000 kematian akibat malaria di seluruh dunia pada tahun 2015, dimana diperkirakan 303.000 (70,6\%) pada anak di bawah usia 5 tahun (WHO, 2017).

Di Indonesia malaria masih menjadi masalah kesehatan walaupun terjadi penurun angka kesakitan malaria dalam periode 2005 sampai 2015 cenderung menurun dari 4,1 per 1000 penduduk berisiko di tahun 2005 menjadi 0,85 per 1000 penduduk. Papua dan Papua Barat merupakan Provinsi dengan Annual Paracite Incidence (API) per 1000 penduduk tertinggi di Indonesia (Profil Kesehatan Indonesia 2015, 2016). Berdasarkan hasil survei riset kesehatan dasar (Riskesdas) tahun 2013 Papua,
Papua Barat dan Nusa tenggara timur merupakan 3 provinsi dengan insiden tertinggi.

Salah satu indikator keberhasilan program pengendalian malaria yaitu pengobatan malaria yang harus dilaksanakan secara efektif untuk memutuskan mata rantai penularan. Pemberian jenis obat harus benar dan tepat waktu yang mengacu penatalaksanaan terapi. Pengobatan efektif adalah pemberian ACT (Artemicin-based Combination Therapy) yang diberikan pada 24 jam pertama pada saat pasien panas dan obat harus diminum habis dalam waktu 3 hari. Berdasarkan hasil Riskesdas 2013 dalam profil Kesehatan Indonesia 2015 (2016) menunjukkan bahwa proporsi pengobatan efektif sebesar 45,5\%, sedangkan hanya ada lima provinsi tertinggi yang mengobati malaria secara efektif lebih dari 50\% yaitu Kepulauan bangka belitung, Sumatra utara, bengkulu, Kalimatan tengah, dan Papua tidak termasuk Papua Barat.

Berbagai upaya telah dilaksanakan untuk program pemberantasan dan pencegahan malaria, baik ditingkat nasional maupun tingkat lokal baik melalui penyuluhan, pembagian kelambu berisektisida namun kenyataannya kasus malaria masih tinggi di wilayah Papua dan Papua Barat, salah satu program yang dilaksanakan untuk pemberantasan malaria pada anak di tingkat Puskesmas melalui program MTBS (Manajemen terpadu Balita Sakit).

Program pemberantasan dan pencegahan malaria ini memerlukan 
dukungan dari berbagai pihak dan peran serta aktif dari masyarakat dalam hal ini dukungan keluarga, Peran aktif keluarga dalam menangani anggota keluarga yang sakit malaria dan perlu mendapat perhatian khusus karena dalam terkadang keluarga menganggap biasa penyakit malaria dan minum obat malaria yang telah didosiskan tidak sesuai, khususnya pada anak yang menderita malaria anak sangat tergantung dengan orang tua atau pengasuh untuk memberi perhatian penuh dan perawatan bagi anak.

Pemberdayaan keluarga dapat dipandang sebagai suatu proses untuk memandirikan keluarga dalam mengenal dan mengambil tindakan untuk mengatasi masalah kesehatannya dengan difasilitasi oleh orang lain, dengan cara meningkatkan kemampuan keluarga untuk melakukan tugas dan fungsi keluarga untuk mengontrol kesehatan keluarga. Untuk memberdayakan keluarga dibutuhkan suatu model yang akan dijadikan sbagai panduan dalam memberikan perawatan, suatu model yang diterapkan akan mempunyai efek yang baik bila dikembangkan berdasarkan kebutuhan pemberi dan pengguna pelayanan keperawatan khususnya bagi perawat anak dan keluarga.

Salah satu konsep pemberdayaan keluarga yang sesuai dengan teori dan konsep keperawatan yang dapat diterapkan pada keluarga adalah Family Centered Nursing. Menurut Friedman (2003) bahwa Family Centered Nursing merupakan kemampuan perawat memberikan Asuhan Keperawatan keluarga sehingga memandirikan anggota keluarga untuk meningkatkan kesehatan seluruh anggota keluarga serta keluarga mampu mengatasi masalah kesehatan yang dialami anggotanya.

Penerapan model Family Centered Nursing ini khususnya pada anak dengan Malaria bertujuan untuk melihat kemandirian keluarga dalam penganan anak dengan malaria, melakukan pendidikan kesehatan pada keluarga, melakukan pembinaan bagi keluarga sehingga keluarga mampu mengatasi masalah kesehatannya khususnya dalam penaganan malaria. Sangat penting bagi perawat menerapkan model teori dengan menggunakan pendekatan proses keperawatan memberikan edukasi yang merupakan salah satu intervensi keperawatan yang mendukung pelaksanaan tugas kesehatan keluarga dalam penanganan malaria yang meliputi mengenal masalah malaria, memutuskan tindakan yang tepat, merawat anak dengan malaria, memodifikasi lingkungan untuk pencegahan malaria dan memanfaatkan pelayanan kesehatan dalam penanganan malaria.

Berdasarkan data puskesmas Sanggeng pada tahun 2015 terdapat 1776 angka kejadian Malaria dan sebanyak $74 \%$ atau 1056 kasus terjadi pada usia kurang dari 15 tahun. Pada tahun 2016 terdapat 1084 kasus malaria dan sebanyak 71 persen atau 1497 kasus terjadi pada usia kurang dari 15 tahun.

Dengan melihat masalah yang terjadi dan upaya yang telah dilakukan maka peneliti tertarik untuk melakukan 
penelitian tentang penerapan model Family Centered Nursing terhadap kemandirian keluarga dalam penanganan malaria pada Anak di wiliayah kerja Puskesmas Sanggeng Kabupaten Manokwari.

\section{B. METODE PENELITIAN}

Desain penelitian adalah model atau metode yang digunakan peneliti untuk melakukan suatu penelitian yang yang memberikan arah terhadap jalannya penelitian (Darma, 2011).

Desain penelitian adalah keseluruhan dari perencanaan untuk menjawab pertanyaan penelitian dan mengantisipasi beberapa kesulitan yang mungkin timbul selama proses penelitian, hal ini penting karena desain penelitian merupakan startegi untuk mendapatkan data yang dibutuhkan untuk keperluan pengujian hipotesis untuk menjawab pertanyaan penelitian sebagai alat untuk mengontrol variabel yang berpengaruh dalam penelitian (Sugiyono, 2010).

Jenis penelitian yang akan digunakan adalah Quasi Eksperimen dengan Pre-Post test Without control Group yang mencari efektifitas atau pengaruh antar variabel yaitu pengaruh variabel model Family Centered Nursing Terhadap kemandirian keluarga dalam Penanganan malaria pada anak dengan pendekatan cross sectional yang mana pengukuran pada obyek atau subyek penelitian dilaksanakan dalam satu kali waktu.

\section{HASIL PENELITIAN}

\section{Analisis Univariat}

\section{a. Karakteristik Responden dan anak Berdasarkan Usia}

Tabel 4.1 Distribusi Usia Responden dan Anak di Puskesmas Sanggeng bulan November 2017

\begin{tabular}{ccccc}
\hline Variabel & N & Mean & SD & (Min-Max) \\
\hline Usia Responden & 30 & 32,87 & 5,98 & $24-46$ \\
Usia Anak & 30 & 29,37 & 17,14 & $8-60$ \\
\hline
\end{tabular}

Sumber : Data Primer 2015

Berdasarkan tabel 4.1 menunjukkan bahwa rerata usia responden adalah 32,87 tahun dengan variasi usia 5,98 tahun. Usia termuda respoden 24 Tahun dan usia tertua adalah 46 Tahun. Rerata usia anak adalah 29,37 bulan dengan variasi usia 17,14 bulan. Usia termuda anak 8 bulan dan tertua 60 Bulan. 


\section{b.Karakteristik Responden Berdasarkan Pendidikan dan Suku}

Tabel 4.2 Distribusi Pendidikan dan Suku Responden di Puskesmas Sanggeng bulan November 2017

\begin{tabular}{|c|c|c|}
\hline Variabel & $\mathbf{N}$ & $\%$ \\
\hline \multicolumn{3}{|l|}{ Pendidikan } \\
\hline SD & 3 & 10 \\
\hline SMP & 7 & 23 \\
\hline SMA & 15 & 50 \\
\hline PT & 5 & 17 \\
\hline Jumlah & 15 & 100 \\
\hline \multicolumn{3}{|l|}{ Suku } \\
\hline Papua & 23 & 77 \\
\hline Non Papua & 7 & 23 \\
\hline Jumlah & 30 & 100 \\
\hline
\end{tabular}

Berdasarkan Tabel 4,2 menunjukkan bahwa rata-rata responden berpendidikan SMA sebanyak 15 orang (50\%), sisanya SMP 7 orang (23\%), Perguruan Tinggi 5 Orang (17\%) dan SD 3 Orang (10\%). Sedangkan untuk responden berdasarkan suku sebagian besar Papua 23 orang $(77 \%)$.

\section{c. Pengetahuan Dan Tingkat Kemandirian Sebelum Dan Sesudah Penerapan Model} Family Centered Nursing

Tabel 4.3 Hasil Analisis Pengetahuan Dan Tingkat Kemandirian Responden Sebelum Penerapan Model Family Centered Nursingd I

Puskesmas Sanggeng Bulan November 2017

\begin{tabular}{llll}
\hline Variabel & Mean & SD & Min-Max \\
\hline Pengetahuan & 60,93 & 14,5 & $36-88$ \\
\hline Tingkat Kemandirian & 1,75 & 0,50 & $1-2$ \\
\hline
\end{tabular}

Dari Tabel 4.3 menunjukkan bahwa skor rerata pengetahuan sebelum penerapan model adalah 60,93, sedangkan skor rerata tingkat kemandirian adalah 1,75 
Tabel 4.4 Hasil Analisis Pengetahuan dan Tingkat Kemandirian

Responden sesudah Penerapan Model Family Centered Nursing

Di Puskesmas Sanggeng bulan November 2017

\begin{tabular}{lccc}
\hline \multicolumn{1}{c}{ Variabel } & Mean & SD & Min-Max \\
\hline Pengetahuan & 83,3 & 7,725 & $68-96$ \\
\hline Tingkat Kemandirian & 2,63 & 0,49 & $2-3$ \\
\hline
\end{tabular}

Dari Tabel 4.3 menunjukkan bahwa skor rerata pengetahuan sesudah penerapan model adalah 83,3, sedangkan skor rerata tingkat kemandirian adalah 2,63

\section{Analisa Bivariat}

Pada Analisis Bivariat ini menunjukkan perbedaan rata-rata pengetahuan dan tingkat kemandirian keluarga sebelum dan sesudah diterapkan model Family Centered Nursing .Berdasarkan Uji Normalitas data karena data tidak berdistribusi normal maka uji yang digunakan adalah Wilcoxon.

Tabel 4.5. Hasil Analisis Perbedaan Pengetahuan Dan Tingkat Kemandirian Keluarga Sebelum Dan Sesudah Diterapkan

Model Family Centered Nursing

\begin{tabular}{|l|l|l|l|l|l|l|}
\hline Variabel & Pengukuran & N & Mean & Peningkatan & \multicolumn{1}{|c|}{ SD } & $\boldsymbol{p}$-Value \\
\hline Pengetahuan & Sebelum & 30 & 60,93 & 22,4 & 14,5 & 0,000 \\
& Sesudah & 30 & 83,33 & & 7,725 & \\
\hline TK.Kemandirian & Sebelum & 30 & 1,75 & 0,88 & 0,50 & 0,000 \\
& Sesudah & 30 & 2,63 & & 0,49 & \\
\hline
\end{tabular}

Pada Tabel menunjukkan bahwa skor rerata pengetahuan sebelum dan sesudah penerapan Model Family Centered Nursing mengalami peningkatan sebesar 22,4 dan tingkat kemandirian keluarga mengalami peningkatan sebesar 0,88. Hasil analisis lebih lanjut didapatkan nilai $p$-Value 0,000 yang berarti ada perbedaan yang signifikan skor rata-rata pengetahuan dan tingkat kemandirian keluarga sebelum dan sesudah diberikan informasi. 


\section{PEMBAHASAN}

Pada pembahasan ini akan dijelaskan makna dari hasil dari penelitian yang diperoleh dan dibandingkan dengan penelitian sebelumnya atau literature yang ada, pembahasan meliputi hasil temuan dan tujuan penelitian.

\section{Karekteristik Responden}

Karakteristik responden dalam penelitian ini meliputi Usia, responden dan usia anak, pendidikan dan suku. Responden dalam penelitian ini adalah ibu dengan usia antara 24 sampai 46 tahun, ini menunjukkan bahwa usia tersebut masuk dalam kategori usia produktif sedangkan anak berusia antara 8 bulan sampai 60 bulan ini masuk dalam kategori balita. Responden mempunyai Tingkat pendidikan paling banyak dengan tingkat pendidikan SMA dan paling terendah dengan pendidikan SD, dan sebagin besar dari suku Papua.

\section{Perbedaan Pengetahuan dan tingkat kemandirian keluarga sebelum dan sesudah penerapan model Family Centered Nursing}

Family Centered Nursing merupakan kemampuan perawat memberikan Asuhan Keperawatan keluarga sehingga memandirikan anggota keluarga untuk meningkatkan kesehatan seluruh anggota keluarga serta keluarga mampu mengatasi masalah kesehatan yang dialami anggotanya.
Penerapan model Family Centered Nursing ini khususnya pada anak dengan Malaria bertujuan untuk melihat kemandirian keluarga dalam penganan anak dengan malaria, melakukan pendidikan kesehatan pada keluarga, sehingga keluarga mampu mengatasi masalah kesehatannya khususnya dalam penaganan malaria.

Pada penelitian ini ditemukan adanya peningkatan yang signifikan dari pengetahuan dan tingkat kemandirian keluarga dengan melihat perbedaan antara sebelum dan sesudah penerapan model, hal ini sejalan dengan penelitian yang dilakukan oleh Erlinda (2015) di Kabupaten Aceh besar menjukkan bahwa penerapan model Family centered nursing terhadap pelaksanaan tugas kesehatan keluarga dalam pencegahan anak dengan ISPA di Kabupaten Aceh besar menunjukkan bahwa model ini sangat efektif meningkatkan kemampuan keluargan mengenal masalah ISPA sebelum dan sesudah penerapan model.

Penerapan model Family Centered Nursing ini, sejalan dengan penelitian yang telah dilakukan oleh Sjattar, dkk (2011) yang menjadi bukti penerapan model Keluarga Untuk Keluarga (KUK), yang merupakan modifikasi dari teori keperawatan Self Care dari Orem dan Family Centered Care Nursing dengan cara edukasi supportif pada keluarga menunjukkan ada pengaruh terhadap kemandirian keluarga yang ditandai dengan adanya peningkatan pengetahuan dan kemandirian keluarga. Penelitian ini juga sejalan dengan penelitan lain yang dilakukan El-Melegi (2016) tentang efektivitas dari model pemberdayaan keluarga (Family 
centered Empowerment) bagi pasien hemodialisa dan keluarganya berdasarkan hasil penelitian ada bahwa dengan penerapan teori ini terjadi peningkatan self efficacy antara pre dan post baik pada pasien yag menjalani terapi hemodialisa maupun pada keluarga.

Berdasarkan teori pembelajaran peneliti juga melalukan penilaian pengetahuan dan observasi tingkat kemandirian keluarga setelah 2 minggu diberi tindakan dukungan edukasi tentang penanganan malaria. Hal ini sejalan dengan penelitian yang dilakukan oleh Laily et al. (2009) tentang bagaimana kebiasaan baru dibentuk menunjukkan bahwa waktu yang dibutuhkan untuk mencapai suatu kebiasaan dilakukan secara otomatis berkisar antara 18-224 hari. Hasil dari penelitian penerapan model family centered nursing menunjukkan bahwa ada peningkatan tingkat kemandirian keluarga sebelum dan sesudah diberikan dukungan edukasi.

Untuk meningkatkan pemahaman dari keluarga tentang penanganan malaria pada penelitian ini peneliti menggunakan booklet.

Orang tua yang mempunyai dengan anak penyakit malaria mengalami stres yang panjang akibat dari bermacam - macam tindakan dan pengobatan yang harus dijalani oleh anak. Oleh karena itu kehadiran orang tua selama prosedur kesehatan terkait dapat secara signifikan mengurangi kecemasan pada anak dan orangtua.

Holm, Patterson, dan Gurney (2003) mendapatkan bahwa orang tua berperan sangat penting untuk memberikan keputusan bagi anak mereka. Karena orang tua lebih mengetahui apa yang dialami oleh anak mereka keterlibatan orangtua, tenaga kesehatan mengalami kesulitan untuk mengetahui apa yang dirasakan oleh anak (Holm et al., 2003).

Namun, orang tua sering merasa kesulitan dalam membuat keputusan hal ini disebabkan orang tua memiliki keterbatasan pengetahuan pada prosedur tindakan yang akan dijalani oleh anak mereka (Holm et al., 2003). Orangtua takut untuk menanyakan tentang hal - hal yang tidak dimengerti oleh mereka (Holmet al.,2003).

Family centered nursing penting untuk perawatan anak dengan malaria karena melibatkan anak dan orang tua.

$\begin{array}{cl}\text { Model Family } & \begin{array}{l}\text { Centered Nursing } \\ \text { bahwa } \\ \text { menggambarkan }\end{array}\end{array}$
merupakan suatu sistem sosial, kelompok terkecil dari masyarakat. Keluarga adalah sekumpulan orang yang dihubungkan karena perkawinan, adopsi dan kelahiran yang bertujuanmenciptakandan mempertahankan budaya yang umum, meningkatkan perkembangan fisik, mental, emosional dan sosial dari individu yang didalamnya menunjukkan pola interaksi yang saling ketergantunga untuk mencapai tujuan bersama (Achjar, 2012).

Friedman dkk, (2003) Sjattar (2012) berpendapat bahwa Family-centered nursing adalah kemampuan perawat memberikan asuhan keperawatan keluarga, sehingga memandirikan anggota keluarga agar tercapai peningkatan kesehatan seluruh anggota keluarganya dan keluarga mampu mengatasi masalah kesehatan (family centered/berorientasi pada keluarga).

Aplikasi dari teori Family centered nursing atau keluarga sebagai pusat keperawatan didasarkan dari pandangan 
keluarga adalah unit dasar untuk perawatan individu dari anggota keluarga, juga merupakan unit dasar dari sebuah masyarakat yang menggambarkan perbedaan budaya, rasial, lingkungan dan sosio ekonomi. Penerapan dari teori ini adalah menggunakan pendekatan proses keperawatan yang di dasarkan pada Friedman model. Pendekatan proses keperawatan dengan fokus keluarga sebagai klien (Family centered nursing) meliputi pengkajian, diagnose keperawatan, intervensi, implementasi dan evaluasi.

Tujuan dari Asuhan keperawatan keluarga dalam penerapan teori Family centered nursing adalah memandirikan keluarga dalam pemeliharaan kesehatan anggota keluarga, untuk itu keluarga harus melakukan lima tugas kesehatan keluarga yaitu: mengenal masalah kesehatan setiap anggota keluarganya, mampu memutuskan tindakan kesehatan yang tepat bagi keluargamerawat anggota keluarga yang mengalami gangguan kesehatan, mempertahankan suasana rumah yang sehat atau memodifikasi lingkungan untuk menjamin kesehatan anggota keluarga, memanfaatkan fasilitas kesehatan.

\section{E. KESIMPULAN}

1. Responden dalam penelitian ini adalah ibu dengan usia antara 24 sampai 46 tahun. Responden mempunyai tingkat pendidikan paling banyak dengan tingkat pendidikan SMA dan paling terendah dengan pendidikan SD, dan sebagian besar dari suku Papua.
2. Skor Pengetahuan keluarga lebih rendah sebelum penerapan model bila dibandingkan dengan setelah penerapan model

3. Tingkat kemandirian keluarga lebih rendah sebelum penerapan model bila dibandingkan setelah penerapan model

4. Ada peningkatan yang signifikan skor pengetahuan dan Tingkat kemandirian keluarga sebelum dan setelah penerapan model.

\section{F. DAFTAR PUSTAKA}

Achjar, KH. (2010). Aplikasi Praktis: Asuhan Keperawatan Keluarga. Jakarta: CV. Sagung Seto

Dharma, KK. (2011). Metodologi Penelitian Keperawatan. Jakarta: CV. Trans Info Media

El-Melegy. A., Al-Zeftawy.A.M., Khaton.S.E. (2016) Effect of family centered empowerment on hemodialysis patient and their caregivers. Journal of nursing education and practice. 6 (11): 119132.

Erlinda, V. (2015). Penerapan Model Family Centered Nursing Terhadap Pelaksanaan Tugas Keluarga dalam Pencegahan ISPA pada anak Balita di Wilayah Kerja Puskesmas Simpang Tiga Kabupaten Aceh Besar. Jurnal Kedokteran yarsi 23(2): 163-186

Laily.P., VanJaarsveld.c.m, Poots.H.W.W., \& Wardle.J (2009). How are Habits 
Formed: Modelling habits formation in the real world. European Journal of social Psychology, 40, 998-1009.

Notoatmodjo, S. (2012). Promosi Kesehatan dan Perilaku Kesehatan. Jakarta: Rineka Cipta

Nurarif .A.H. dan Kusuma. H. (2016). Asuhan Keperawatan Praktis Berdasarkan Penerapan Diagnosa Nanda , NIC NOC Dalam Berbagai Kasus Jilid 1. Jogjakarta: MediAction

Nurarif .A.H. dan Kusuma. H. (2016). Asuhan Keperawatan Praktis Berdasarkan Penerapan Diagnosa Nanda , NIC NOC Dalam Berbagai Kasus Edisi Revisi Jilid 1. Jogjakarta: MediAction

Nurarif, AH \& Kusuma, H. (2016). Aplikasi Asuhan Keperawatan Berdasarkan Diagnosa Medis dan Nanda NICNOC. Yogjakarta: MediAction

Schumacher R.F \& Spinelli, E. (2012). Malaria in Children. Mediter J. Hematol Infect. Dis, 4 (1): e2012073

Setiadi. (2008). Asuhan Keperawatan Keluarga. Edisi Pertama. Yogyakarta: Graha Ilmu

Setiawati, dkk. (2008). Asuhan Keperawatan Keluarga. Jakarta: Agung Wijaya

Sjattar, EL. (2012). Model Integrasi Self Care dan Family Centered Nursing. Yogyakarta: Pustaka Timur
Soedarto. (2011). Malaria. Jakarta: CV. Sagung Seto

Sugiyono. (2012). Metode Penelitian Kuantitatif dan $R \& D$. Jakarta: Alfabeta

Sunarti \& Shinta. (2011). 14 Penyakit Paling sering Menyerang dan Sangat Mematikan. Jakarta: Wardi

Sorontou, Yohanna. (2013). Ilmu Malaria Klinik. Jakarta: EGC

Wijaya, Indriani. (2013). Asma Brongkial. Yogyakarta: Pinang Merah

World Health Organisation. (2017). Malaria Report. WHO 